\title{
Antioestrogens in Treatment of Breast Cancer: Value of Nafoxidine in 52 Advanced Cases
}

\author{
H. J. G. BLOOM, EVELYN BOESEN
}

British Medical fournal, 1974, 2, 7-10

\section{Summary}

The synthetic non-steroidal antioestrogen nafoxidine (U-11, $100 A$ ) was given by mouth to 52 women with locally advanced or metastatic breast cancer, in $85 \%$ of whom the disease had become resistant to, or relapsed after, previous endocrine treatment. The objective response rate (complete or partial regression of disease) among 48 cases treated for at least four weeks was $37 \%$. Tumours in soft tissue seemed to respond better than skeletal metastases. The patients in all but one of the 52 cases were postmenopausal. Those who had had an objective response to previous hormone treatment had a greater chance of deriving benefit from nafoxidine than those who had been resistant to hormone treatment.

Side effects of nafoxidine were dryness of skin, increased loss of scalp hair, and heightened sensitivity to sunlight. None were serious, and they could be lessened by protection from solar radiation or a decrease in dosage. No obvious depression of thyroid or adrenal function or obvious water retention or masculinization was seen. Cataract was a possible complication.

This clinical trial was preceded by laboratory studies in which a transplantable oestrogen-dependent tumour in the Syrian hamster was notably inhibited by the administration of nafoxidine. This experimental model may prove useful in screening potentially useful antioestrogenic agents against breast cancer before a human trial.

\section{Introduction}

The uptake and retention of oestrogen in high concentration by breast cancer tissue may be related to the tumour's hor-

Royal Marsden Hospital and Chester Beatty Research Institute, Royal Marsden Hospital and Chester Beatty
Institute of Cancer Research, London S.W.3

H. J. G. BLOOM, F.R.C.P., F.F.R., Consultant Radiotherapist

EVELYN BOESEN, M.D., B.S., Senior Lecturer

mone dependence (Folca et al., 1961; Jensen et al., 1967; Jensen et al., 1971; Hähnel et al., 1971; Braunsberg et al, 1973). The presence of active tissue oestrogen receptors in experimental and human mammary tumours can be shown by invivo and in-vitro techniques using isotope-labelled oestradiol (Jensen et al., 1967; Johansson et al., 1970; Fehenty et al., 1971; Wittliff et al., 1971; Steggles and King, 1972; Terenius, 1972). Such in-vitro studies may ultimately prove of value in discovering oestrogen dependence in women with advanced breast cancer and in predioting the likelihood of a response to antioestrogenic agents or to endocrine ablation procedures aimed at inhibiting endogenous oestrogen.

The strong affinity for labelled oestradiol of centain target organs and their tumours, both experimental and human, can be effectively blocked by synthetic non-steroidal compounds such as nafoxidine (U-11, 100A), ethamoxytriphetol, and clomiphene (Jensen et al., 1967; Sander, 1969; Terenius, 1971; Jensen et al., 1971). The ability of such agents to interfere with oestradiol binding in target tissues may be explained by the competitive uptake of these compounds by cytoplasmic oestrogen receptors. By causing oestrogen deprivation of tumour tissue antioestrogens may prove of value as therapeutic agents for advanced breast cancer. They may also serve as indicators of tumour hormone dependence, and in such cases further endocrine therapy, including ablation procedures, may be worthwhile when the initial response to antioestrogen is no longer sustained.

In 1967 we reponted the marked in-vivo inhibitory effect of an oestrogen antagonist, nafoxidine (U-11, 100A), on the transplanted oestrogen-induced renal tumour of the Syrian hamster (Bloom et al., 1967). In this model the effect of nafoxidine ( $1 \mathrm{mg}$ subcutaneously daily) was abolished by the simultaneous administration of oestradiol $(0.2 \mathrm{mg}$ subcutaneously daily). After these laboratory experiments we suggested that nafoxidine might be of value in the treatment of patients with advanced cancer arising in the breast, endometrium, and possibly the kidney (Bloom et al., 1967).

We report here our experience with nafoxidine in the treatment of 52 women with advanced mammary cancer, most of whom had been resistant to, or had broken away from, endocrine control. 


\section{Patients and Methods}

\section{TEST SUBSTANCE}

Nafoxidine (U-11, 100A) is a diphenyldihydronophthalene derivative with the formula $1-\{2-[\mathrm{p}-(3,4$ - dihydro-6-methoxy2-phenyl-1-naphthyl) phenoxy] ethyl $\}$ pyrrolidine hydrochloride. It is a synthetic non-steroidal antioestrogen which was prepared in the laboratories of Upjohn Ltd. It is related structurally to clomiphene and also to chlorotrianisene and is devoid of androgenic, progestational, and gonadotrophininhibiting properties. It does not seem to interfere with pituitary-thyroid or pituitary-adrenal funotion. In high doses in some species it may behave as a weak oestrogen. The principal action of nafoxidine is to combine with cytoplasmic oestrogen receptor sites in target tissues forming a stable complex, thereby preventing the full action of oestrogen. In most experimental animals it has been shown to inhibit the in-vitro or in-vivo binding of labelled oestradiol to normal oestrogen dependent target organs such as the uterus, vagina, and breast, and also to mammary tumours induced by 7, 12dimethylbenzanthracene in the rat (Jensen et al., 1967; Terenius, 1971).

\section{PATIENTS}

Fifty-two women with advanced breast cancer were treated with nafoxidine. Their age range was 31 to 73 years with a mean of 56 years. All but one were postmenopausal by vintue of either earlier endocrine ablation or natural change. Fontyfive patients $(85 \%)$ had received previous endocrine treatment and nine had also received cytotoxic drugs. In 38 cases widespread metastases were present when nafoxidine was started. In the remaining 14 cases the tumour was locally advanced and confined to the chest wall or regional nodes.

\section{TREATMENT}

Nafoxidine (30 mg tablets) was given orally in doses of $60-90$ $\mathrm{mg}$ three times a day for 1-36 months. Fonty-one patients were treated for at least six weeks. Of the remaining 11 patients four died of progression of the tumour within four weeks and seven had their treatment stopped at six weeks because of continued or increasing symptoms due to the tumour. Two other patients died of tumour progression after seven weeks' treatment. In two women showing tumour regression the dose of nafoxidine was reduced to $30 \mathrm{mg}$ three times a day; at this dose regression was maintained and side effects were less noticeable.

\section{CRITERIA OF CLINICAL RESPONSE}

We defined "complete tumour regression" as the disappearance of all palpable or visible radiological lesions for at least eight weeks without the appearance of any new lesions. Radiological signs of recalcification were accepted as evidence of tumour regression in patients with bone deposits. A "pantial response" was one where the tumour was reduced more than $50 \%$ in size or where it regressed by at least $50 \%$ in some sites while remaining stationary in others.

\section{Results}

Complete tumour regression was seen in seven patients and a pantial response was seen in 11 others. Some benefit from treatment was therefore obtained by 18 out of $48(37 \%)$ patients: the four patients who died before four weeks of treatment were completed have been excluded from our figures. Complete or partial regression was observed in 11 of the 26 patients with locally advanced tumours involving the chest wall or nodes, and of the 14 of these patients who had tumours confined to the chest wall or nodes six responded. Only two of the 24 patients with skeletal metastases showed radiological signs of recalcification though pain was relieved in a further six such cases. A partial response of pulmonary metastases was seen in four out of seven cases and of hepatic metastases in two of six cases.

The duration of the response to nafoxidine ranged from two to 36 months with a mean value of 11 months and a median value of nine months. Of the 18 women in whom objective regression occurred the response was maintained for six months in 17 and for one to three years in eight. Five patients showing a total or pantial response are still under treatment (table I). Compared with the resistant cases a greater proportion of patients who improved with nafoxidine had responded previously to other hormonal treatment.

TABLE I-Duration of Response to Nafoxidine

\begin{tabular}{|c|c|c|c|c|c|}
\hline $\begin{array}{l}\text { Duration of response (months) } \\
\text { No. of cases }\end{array}$ & $\begin{array}{r}<3 \\
1\end{array}$ & $\begin{array}{c}6-9 \\
9\end{array}$ & $\frac{10-12}{5}$ & $\begin{array}{c}20-36 \\
3\end{array}$ & $\begin{array}{c}\text { Total } \\
18^{*}\end{array}$ \\
\hline
\end{tabular}

* Total includes five cases that still responded to treatment after $6,6,7,10$, and 30 months.

\section{SIDE EFFECTS}

Patients who were treated with nafoxidine for more than two months complained of dryness of the skin and most also experienced cutaneous photosensitivity to sunlight. Six patients suffered increased loss of scalp hair and four women noticed a reduction in hair pigmentation. The skin and hair changes usually improved when the dose of nafoxidine was reduced from $270 \mathrm{mg}$ to $180 \mathrm{mg}$ daily. This dose reduction was made without loss of tumour control. No gastrointestinal or cardiovascular complications were seen nor any appreciable deterioration in liver or marrow function which could be ascribed to the antioestrogen. There was no evidence of any change in thyroid or adrenal function, as judged from clinical examination, plasma contisol levels, and thyroid function tests.

The most serious side effeot was progressive bilateral cataract in a woman aged 46 who received nafoxidine for three years, during which time excellent control of very advanced metastatic disease was achieved. Both cataraots were successfully extracted. Because of a preliminary report that nafoxidine caused cataract in dogs and cats (Demissianos H.V., personal communication) and clomiphene, which is structurally related to nafoxidine, in very high doses $(40 \mathrm{mg} \mathrm{kg} /$ day) had produced lens opacities in $9 \%$ of treated rats and in one out of 14 dogs (quoted by Swyer, 1965) we searched for eye changes in hamsters used in our initial laboratory experiments (Bloom et al., 1967). Mr. J. M. Mallett examined these animals ophthalmoscopically after six and again after 11 weeks of continuous treatment with nafoxidine but found no lens changes. The hamsters, however, were caged in the normal animal rooms and not exposed to direct sunlight. Lens changes induced by nafoxidine may be part of a more general photosensitization effect rather than a direct druginduced change (Cobb, 1972). We now recommend that patients receiving nafoxidine should avoid direct exposure of the skin to strong sunlight and should wear sun glasses. We intend to investigate the value of a high-dose vitamin $A$ and calcium carbonate preparation (Sylvasun) in protecting patients from solar radiation (Turner et al., 1971).

After a complete or pantial response to nafoxidine was aohieved with an initial standard dose of $90 \mathrm{mg}$ three times a 
day treatment was continued at a maintenance level of $60 \mathrm{mg}$ three times a day. It may be possible to reduce the dose even further without loss of tumour control. In patients who derive prolonged benefit from nafoxidine a possible risk of cataract may be justified since this complication is remediable. But seemingly few cases are likely to develop serious lens changes. They occurred in only one of our 48 cases and in none of the 23 cases in the European Organization for Research and Treatment of Cancer trial (E.O.R.T.C., 1972).

\section{FACTORS AFFECTING RESPONSE TO ANTIOESTROGENS}

\section{Age and Menopause}

Antioestrogen agents might be expected to be of special value in younger patients with higher blood oestrogen levels. Maass et al. (1972) found high-affinity oestradiol receptors in a comparable propontion of premenopausal (46\% of 43 cases) and postmenopousal (39\% of 121 cases) patients. Most authors, however, have found a high concentration of tumour oestrogen receptors in women past the menopause (Korenman and Dukes, 1970; Wittliff et al., 1971; Fehenty et al., 1971; Hähnel et al., 1971; Spaeren et al., 1973).

All patients treated with nafoxidine in the recent E.O.R.T.C. Breast Cancer Group (1972) trial were postmenopausal (natural or induced), as were those cases in the studies of Cole et al. (1971) and of Ward (1973), who were treated with another antioestrogenic agents, tamoxifen (I.C.I. 46474). All but one of our 48 assessable patients were postmenopausal (table II). Though it is impossible to conclude that benefit from antioestrogens is significantly related to age or to menopausal state the evidence suggests that postmenopausal patients are more likely to respond than younger women.

TABLE II-Proportion of Responders to Nafoxidine according to Menstrual Status

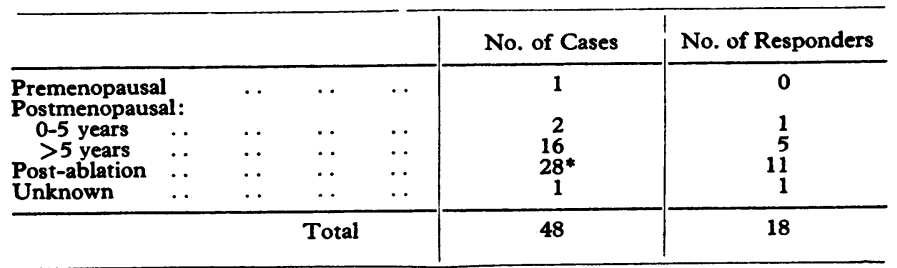

*Oophorectomy was performed in 24 cases and hypophysectomy in four.

\section{Response to Previous Endocrine Treatment}

Our study indicated that patients who showed a response to earlier hormone treatment or endocrine ablation were more likely to benefit from antioestrogen therapy (nine out of 15) than previously resistant cases (one out of 20). The response of the remaining 13 patients to previous endocrine therapy was not assessable in six and no therapy was given to seven; four patients from each group responded to nafoxidine. It is clear from our study and that of Cole et al. (1971) that resistance which developes after an initial response to endocrine treatment is no reason to withhold a subsequent trial of antioestrogens. It was interesting to observe partial tumour regression with nafoxidine in a patient who had undergone hypophysectomy for metastatic breast cancer 12 years previously and to which she had responded. This woman had also shown objective improvement with androgens and cytotoxic drugs after hypophysectomy and before the antioestrogen was given for yet a further relapse. Three other hypophvsectomized patients in the series failed to respond to nafoxidine, though in one the operation had been of considerable benefit.

\section{Tumour Site}

Soft tissue lesions seemed to respond better to nafoxidine than skeletal metastases. Eleven of our 26 cases of advanced local disease showed a distinct objective response to treatment compared with radiological signs of bone healing in only two of 24 cases with skeletal metastases. Even when cutaneous and visceral deposits regress bony depasits in the same patient may show no signs of healing. Four of seven patients with pulmonary metastases responded well to treatment. Ward (1973), working with another antioestrogen, tamoxifen (I.C.I. 46474), also concluded that soft tissue deposits responded better than skeletal lesions.

\section{Tumour Stage and Grade}

Maass et al. (1972) found no correlation between the oestradiol-binding capacity and the clinical extent of breast cancer, the incidence of receptors being similar in patients with tumours that were operable (67 out of $164 ; 41 \%$ ), locally advanced (5 out of $10 ; 50 \%$ ), or with skin and lymph node spread (7 out of 20;35\%). Neither Feherty et al. (1971) nor Hähnel et al. (1971) were able to find any histological features (including tumour grade, tumour infiltration, and cell type) which could be related to oestradiol-binding capacity.

\section{Tumour-free Interval}

No correlation could be found between treatment response and tumour-free interval (table III); as many patients presenting with generalized disease responded as those with tumour-free intervals of more than five years.

TABLE III-Distribution of Responders to Nafoxidine according to Tumour-free Interval

\begin{tabular}{|c|c|c|c|c|c|}
\hline \multicolumn{2}{|c|}{ Tumour-free interval (years): } & \multirow{2}{*}{$\frac{\mathrm{Nil}}{\frac{10^{*}}{5}}$} & \multirow{2}{*}{$\begin{array}{r}<2 \\
16 \\
6\end{array}$} & \multirow{2}{*}{$\frac{2-5}{13}$} & \multirow{2}{*}{$\begin{array}{r}>5 \\
9 \\
5\end{array}$} \\
\hline $\begin{array}{l}\text { No. of cases } \\
\text { No. of responders }\end{array}$ & $\begin{array}{l}. \\
.\end{array}$ & & & & \\
\hline
\end{tabular}

*These patients presented with metastases.

\section{Discussion}

In our study 18 of the $48(37 \%)$ women with advanced breast cancer showed appreciable tumour regression after treatment for at least four weeks with nafoxidine. These results were especially encouraging since no fewer than 41 out of 48 $(85 \%)$ of the cases were resistant to, or had relapsed from, previous endocrine treatment. As might have been expected, women who had previously responded to endocrine treatment were more likely to respond to nafoxidine (nine out of 15 cases) than those who had seemed to be hormone-resistant (one out of 20 cases). Nafoxidine was of special value in women with locally advanced disease, an objective response occurring in all the $26(42 \%)$ such patients. Oestrogens and progestins also seem to have a greater therapeutic effect in breast cancer patients with advanced local disease than in those with generalized metastases (Jones et al., 1971).

Despite the administration of nafoxidine evidence of oestrogen activity was seen in the vaginal smears in all the six cases examined. Interestingly this was so even when the pretreatment smear showed no or low oestrogen activity. A similar observation was made by the E.O.R.T.C. group (1972). From this we can only presume that the action of nafoxidine may not be uniform at all target sites. The interpretation of such smears is often difficult, but the persistence of oestrogen action on target organs cannot readily be confirmed by other means and was not attempted in the present study. Clearly 
further investigation of this unexpected observation is needed.

Antioestrogens, like other hormonal agents, are effective only in some advanced breast cancer cases. Presumably a response is more probable in women whose tumours possess a substantial concentration of oestrogen receptors. Finding a high concentration of oestrogen-binding capacity in biopsy specimens, using tritium-labelled oestradiol, may be a means of predicting this type of endocrine dependence (Hähnel et al., 1971; Maass et al., 1972) and of assessing the likelihood of a particular patient's response to hormone therapy or to endocrine ablation procedures. Breast tumours deficient in oestrogen receptors and therefore in oestrogen-binding capacity usually fail to respond to endocrine treatment. Engelsman et al. (1973) reported only two objective remissions after hormone treatment in 20 patients with receptor-negative tumours, compared with 14 out of 17 women with receptorpositive tumours. Not all patients in whom receptors can be shown, however, respond usefully to treatment (Jensen et al., 1971; Braunsberg et al., 1973). This may be explained by the presence of a mixed population of tumour cells, with or without oestrogen receptors, and by different areas in the same tumour showing either high or low oestrogen-binding capacity (Hähnel et al., 1971). We need to determine whether the inclusion of an antioestrogen such as nafoxidine in the in vitro test system based on tumour uptake of labelled oestradiol (Terenius, 1971) can achieve greater accuracy in predicting hormone responsiveness and in selecting patients for treatment.

It seems that in about one in three cases of advanced breast cancer in postmenopausal women an appreciable number of oestrogen-binding receptors are present and that most of these tumours will respond to antioestrogens or endocrine ablative procedures (Terenius, 1971; Jensen et al., 1971; Maass et al., 1972). During our study the E.O.R.T.C. Breast Cancer Group reponted objective remissions in 8 out of 25 $(32 \%)$ cases of advanced breast cancer treated for at least two weeks with nafoxidine in a co-operative study at four centres (E.O.R.T.C., 1972). These results agree closely with our finding that 18 out of $48(37 \%)$ cases treated with nafoxidine for at least a month showed an objective response.

Tamoxifen, another antioestrogen used recently in the treatment of advanced breast cancer, is the transisomer of 1 (p- $\beta$-dimethylaminoethoxy phenyl)-1, 2-diphenylbut-1ene, which is also chemically related to clomiphene. Cole et al. (1971) gave tamoxifen to 46 postmenopausal women with late or recurrent breast cancer, most of whom had previously received some treatment with hormones or cytotoxic agents. Ten cases $(22 \%)$ showed a good objective response-a rate comparable to that obtained in two control groups, one treated with di-ethylstilboestrol (objective response in 16 out of $24 ; 25 \%$ ) and the other with methylandrostenediol (objective response in 10 out of $60 ; 16 \%$ ). Recently Wand (1973) has reported tumour arrest or regression in $69 \%$ of 68 breast cancer cases treated with tamoxifen. This remarkably high response rate is, in fact, compatible with the unusually high prevalence $(70 \%)$ of oestrogen receptors found in breast cancer patients by Feherty et al. (1971). Ward's
(1973) criteria of objective change,however, were less critical than ours, and he included some cases showing only "arrested" disease and 26 patients in whom the reduction in tumour size ranged between " $50 \%$ and zero."

The continued search for antioestrogens as antifertility agents will no doubt lead to the discovery of more potent and perhaps more useful agents against oestrogen dependent tumours. In-vitro and in-vivo laboratory models using oestrogen dependent tumours or normal target tissues may prove useful for screening potentially effective agents before human trial (Bloom et al., 1967).

\section{Conclusions}

Nafoxidine (U-11, 100A) and other antioestrogens may come to play an important role in the treatment of women with advanced breast cancer which is no longer amenable to local measures and which also may have become resistant to previous endocrine treatment. The antioestrogens may prove more effective in the primary endocrine management of this disease than standard hormonal agents (oestrogens, androgens, and corticosteroids). Furthermore, nafoxidine is apparently devoid of serious side effeots on the cardiovascular system and gastrointestinal tract and does not cause masculinization. Cutaneous dryness and photosensitivity are common but not serious complications. These, together with the possible small risk of cataraot, can probably be avoided by protection from solar radiation or reduction in the dose of nafoxidine.

\section{References}

Bloom, H. J. G., Roe, F. J. C., and Mitchley, B. C. V. (1967). Cancer, 20,

2118.
Braunsberg, H., et al. (1973). Lancet, 1, 163.

Cobb, L. M. (1972). Personal communication.

Cole, M. P., Jones, C. T. A., and Todd, I. D. H. (1971). British fournal of Cancer, 25, 270.

Engelsman, E., Persijn, J. P., Korsten, C. B., and Cleton, F. J. (1973). British Medical fournal, 2, 750.

E.O.R.T.C., Breast Cancer Group (1972). European fournal of Cancer, 8, 387.

Feherty, P., Farmer-Brown, G., and Kellie, A. E. (1971). British fournal of Cancer, 25, 697.

Folca, P. J., Glascock, R. F., and Irvine, W. T. (1961). Lancet, 2, 796.

Hähnel, R., Twaddle, E., and Vivian, A. B. (1971). Steroids, 18, 681.

Jensen, E.' V., Block, G. E., Smith, S., Kyser, K., and DeSombre, E. R. (1971). National Cancer Institute Monograph, no. 34, p. 55

Jensen, E. V., DeSombre, R., and Jungblut, P. W. (1967). In Endogenous Factors Influencing Host-Tumor Balance, ed. R. W. Wissler, T. L. Dao,
Fing Factors Influencing Host-Tumor Balance, ed. R. W. Wissler,

Johansson, H., Terenius, L., and Thorén, L. (1970.) Cancer Research, 30, 692.

Jones, V., et al. (1971). Lancet, 1, 1049.

Korenman, S. G., and Dukes, B. A. (1970). Clinical Endocrinology and Metabolism, 30, 639.

Maass, H., Engel, B., Hohmeister, H., Lehman, F., and Trams, G. (1972). American Yournal of Obstetrics and Gynecology, 113, 377.

Sander, S. (1969). Pathologica et Microbiologica Scandinavica, 75, 520.

Spaeren, U., Olsnes, S., Brennhovd, I., Efskind, J., and Pihl, A. (1973). European fournal of Cancer, 9, 353.

Steggles, A. W., and King, R. J. B. (1972). European fournal of Cancer, 8, 323. Swyer, G. I. M. (1965). In Agents Affecting Fertility, ed. C. R. Austin and J. S. Perry, p. 180 . London, Churchill.

Terenius, L. (1971). European fournal of Cancer, 7, 57.

Terenius, L. (1972). European fournal of Cancer, 8, 55.

Turner, A. C., Barnes, R. M., and Green, R. L. (1971). The Practitioner, 206,662 .

Ward, H. W. C. (1973). British Medical fournal, 1, 13.

Ward, H. W. C. (1973). British Medical fournal, 1, 13.
Wittliff, J. L., et al. (1971). Cancer Research, 32, 1983. 